\title{
Correction to: Use of daily electronic patient-reported outcome (PRO) diaries in randomized controlled trials for rheumatoid arthritis: rationale and implementation
}

Clifton O. Bingham $11^{1 *}$, Carol L. Gaich², Amy M. DeLozier ${ }^{2}$, Kathryn D. Engstrom², April N. Naegeli², Stephanie de Bono ${ }^{2}$, Pixy Banerjee ${ }^{3}$ and Peter C. Taylor ${ }^{4}$

\section{Correction to: Trials}

https://doi.org/10.1186/s13063-019-3272-0

After publication of the original article [1], the authors have notified us of an error in language used in the text:

- The first sentence of the 6th paragraph under the Methods sections should read "Training was completed for each individual patient."

- The first sentence of the 3rd paragraph under Training of patients and site staff should read: "The site staff underwent face-to-face training and handson experience with the devices at investigator meetings or online training modules and took 2 hours to complete on average."

The phrase "took 2 hours to complete on average" was moved from the first sentence to the second one.

\section{Author details}

'Divisions of Rheumatology and Allergy and Clinical Immunology, Johns, Hopkins University, 5200 Eastern Avenue, MFL Center Tower Room 404, Baltimore, MD 21224, USA. ${ }^{2}$ Eli Lilly and Company, Indianapolis, USA. ${ }^{3}$ Eli Lilly Services India Private Limited, Bangalore, India. ${ }^{4}$ Botnar Research Centre, Nuffield Department of Orthopaedics, Rheumatology and Musculoskeletal Sciences, University of Oxford, Windmill Road Headington, Oxford, UK.

Received: 24 May 2019 Accepted: 24 May 2019

Published online: 04 June 2019

\section{Reference}

1. Bingham CO, et al. Use of daily electronic patient-reported outcome (PRO)

diaries in randomized controlled trials for rheumatoid arthritis: rationale and implementation. Trials. 2019;20:182. https://doi.org/10.1186/s13063-019-3272-0.

\footnotetext{
* Correspondence: cbingha2@jhmi.edu; clifton.bingham@jhmi.edu 'Divisions of Rheumatology and Allergy and Clinical Immunology, Johns, Hopkins University, 5200 Eastern Avenue, MFL Center Tower Room 404, Baltimore, MD 21224, USA

Full list of author information is available at the end of the article
}

(c) The Author(s). 2019 Open Access This article is distributed under the terms of the Creative Commons Attribution 4.0 International License (http://creativecommons.org/licenses/by/4.0/), which permits unrestricted use, distribution, and reproduction in any medium, provided you give appropriate credit to the original author(s) and the source, provide a link to the Creative Commons license, and indicate if changes were made. The Creative Commons Public Domain Dedication waiver (http://creativecommons.org/publicdomain/zero/1.0/) applies to the data made available in this article, unless otherwise stated. 